NBER WORKING PAPER SERIES

\title{
SUPPLY RESPONSES TO DIGITAL DISTRIBUTION: RECORDED MUSIC AND LIVE PERFORMANCES
}

Julie Holland Mortimer

Chris Nosko

Alan Sorensen

Working Paper 16507

http://www.nber.org/papers/w16507

\author{
NATIONAL BUREAU OF ECONOMIC RESEARCH \\ 1050 Massachusetts Avenue \\ Cambridge, MA 02138 \\ October 2010
}

The data for this study were provided by Pollstar and Nielsen SoundScan, and we thank Chris Muratore, Gary Bongiovanni, and Alan Krueger for their help in assembling the data. Elias Bruegmann, Natalie Chun, Yani Ioannou, Anna Levine, Maisy Samuelson, Matt Schefer, and Hassan Sultan provided outstanding research assistance. We are thankful to Tim Bresnahan, Austan Goolsbee, and Rob Porter for helpful comments. Any errors are ours. The views expressed herein are those of the authors and do not necessarily reflect the views of the National Bureau of Economic Research.

NBER working papers are circulated for discussion and comment purposes. They have not been peerreviewed or been subject to the review by the NBER Board of Directors that accompanies official NBER publications.

(C) 2010 by Julie Holland Mortimer, Chris Nosko, and Alan Sorensen. All rights reserved. Short sections of text, not to exceed two paragraphs, may be quoted without explicit permission provided that full credit, including $\odot$ notice, is given to the source. 
Supply Responses to Digital Distribution: Recorded Music and Live Performances Julie Holland Mortimer, Chris Nosko, and Alan Sorensen

NBER Working Paper No. 16507

October 2010

JEL No. L0,L82

\begin{abstract}
Changes in technologies for reproducing and redistributing digital goods (e.g., music, movies, software, books) have dramatically affected profitability of these goods, and raised concerns for future development of socially valuable digital products. However, broader illegitimate distribution of digital goods may have offsetting demand implications for legitimate sales of complementary non-digital products. We examine the negative impact of file-sharing on recorded music sales and offsetting implications for live concert performances. We find that file-sharing reduces album sales but increases live performance revenues for small artists, perhaps through increased awareness. The impact on live performance revenues for large, well-known artists is negligible.
\end{abstract}

Julie Holland Mortimer

Department of Economics

Harvard University

207 Littauer Center

Cambridge, MA 02138

and NBER

mortimer@fas.harvard.edu

Chris Nosko

Harvard University

cnosko@fas.harvard.edu

\author{
Alan Sorensen \\ Graduate School of Business \\ Stanford University \\ 518 Memorial Way \\ Stanford, CA 94305-5015 \\ and NBER \\ asorensen@stanford.edu
}




\section{Introduction}

New information technologies in the past decade have radically changed the methods of distributing information goods (i.e., products that can be digitalized). These technologies make new distribution channels available to consumers, but also raise the risk of illegitimate redistribution. Understanding how firms can create and distribute information goods while still protecting their intellectual property has been the core issue of many policy debates, including those surrounding the passage of the Digital Millenium Copyright Act (DMCA), the Uniform Computer Information Transactions Act (UCITA), and a landmark U.S. Supreme Court case (MGMv. Grokster). The fundamental economic concern is that redistribution technologies may threaten markets for information goods by making it difficult for producers to capture the returns to their investments.

However, concerns about the viability of markets for digitally redistributable products may be tempered if firms can recover their investments through the sale of complementary, nondigital goods. Redistribution of the digital good may increase demand for the complementary good, partially offsetting the losses due to illegal redistribution of the digital good. The implication, as argued by Teece (1986), is that public policy aimed at promoting innovation should not ignore the impact of an innovation on goods or assets that are complementary to it.

In this paper we study firms' responses to digital redistribution technologies in the specific context of the music industry. Large-scale file-sharing of recorded music began with the entry of Napster in 1999, and recorded music has been at the forefront of debates about the impact of digital distribution ever since. Several empirical studies have focused on measuring the extent to which illegal downloads displaced legal sales. ${ }^{1}$ In contrast, our primary focus is to examine how file-sharing affected the complementary market for live concert performances. To address this question, we construct an extensive dataset of concert events and album sales. The concert data contain information on over 200,000 concerts between 1995 and

\footnotetext{
${ }^{1}$ See, for example, Blackburn (2004), Hong (2005), Liebowitz (2004), Oberholzer and Strumpf (2004), Rob and Waldfogel (2004), and Zentner (2003).
} 
2004 performed by over 12,000 artists. We are able to combine detailed sales data with the concert data for a sample of 1,806 artists. $^{2}$

We expect two kinds of effects of recorded music file-sharing on live concert performances. One effect is a demand shift: if recorded music and live performances are complements (e.g., because a concert is more enjoyable if you have listened to the recorded music ahead of time), then increases in the consumption of recorded music due to file-sharing should lead to increased demand for live performances. The second effect is a supply shift: to the extent that file-sharing reduces the profits from selling recorded music, we would expect artists to reallocate effort toward concert tours and away from recording new albums. Both of these effects imply that concert activity should increase after the entry of Napster in 1999 and the adoption of large-scale file-sharing. In fact, the number of concert events increased sharply beginning in 2001, as shown in Figure 5. The surge in the number of concerts is a sharp contrast to the concomitant decline in album sales, which the record industry blamed on file-sharing.

Our objective is to document various trends in the production of recorded music and live performances, and ask whether those trends are consistent with the two effects described above. At the most basic level, we look for breaks in trend like the one shown in Figure 1. Further, we examine variation in trends across artist types. File-sharing may increase awareness of smaller, more obscure bands by making their music available from more sources and at a much lower cost (or for free in the case of illegal file-sharing). Broader awareness of these bands could increase demand for their concert performances. Similarly, while filesharing may offset some album sales, for small bands this may be mitigated by increased sales resulting from a larger potential fan base, again due to increased awareness. On the other hand, file-sharing may have a relatively small impact on concert performances for large, "superstar" bands. These bands were already well-known and their music was already widely

\footnotetext{
${ }^{2}$ We collect data in both markets going back to 1993. In several of our analyses, we construct variables (e.g., growth rates) that limit our analyses to start no earlier than 1995, and for consistency we report all analyses for the period of 1995 and later. The general implications of the analyses are not sensitive to the inclusion or exclusion of data prior to 1995.
} 
played prior to file-sharing, so file-sharing may have had little impact on demand for their concerts. Similarly, for large bands we expect file-sharing to substantially displace album sales with little mitigating expansion in overall listenership. In summary, we expect small bands to experience a greater increase in concert revenues and less of a decline in album sales than large, highly popular bands following the entry of Napster.

We examine this hypothesis by ranking artists by concert revenues and album sales, and then calculating growth rates in concert revenues and album sales by rank (i.e., we calculate the growth rate by comparing the concert revenues of the $5^{\text {th }}$-ranked artist in 1996 to the $5^{\text {th }}$-ranked artist in 1995). Consistent with prior studies, we find a substantial decline in album sales following the entry of Napster. We also find that concert revenues grew at a substantially higher rate following the entry of Napster. Furthermore, we find that concert revenues for the highest-ranked artists were mostly unaffected by the entry of Napster, while revenues for smaller, lower-ranked artists grew at a much faster rate following Napster than before Napster. On the other hand, album sales for top-ranked artists fell dramatically following the entry of Napster, while album sales for small artists experienced a relatively smaller decline. Hence, superstar artists appear to receive little or no benefit from filesharing in terms of increasing demand for their concerts, presumably because people were widely aware of their music prior to file-sharing. For smaller artists, however, our findings are consistent with file-sharing increasing awareness of the artists' music and consequently increasing demand for live concert performances by those artists, as well as mitigating any loss in recorded music sales from illegal downloading. These results appear to be fairly consistent whether the analysis is conducted at a national level or separately for different markets.

While our study focuses on the music industry, the economic phenomena we analyze are clearly relevant in many other markets. For example, digital copies of movies may cut into home video sales, but may also lead to higher demand for movie-related merchandise. An author's royalties from book sales may be reduced if the book is digitally shared, but the increased readership may lead to profits on the lecture circuit. Mass sharing of a pirated software program may displace paid licenses for that program, but may also generate increased 
sales of complementary physical products or technical support services.

The paper proceeds as follows. In the next section we provide a brief description of the music industry, and we describe our data sources. In Section 3 we describe aggregate trends in concert activity and recorded music sales; in Section 4 we analyze more detailed artist-level data for the sample of 1,806 artists for whom we observe both concert revenues and CD sales. Section 5 provides a discussion of our findings and concludes.

\section{Background \& Data}

\subsection{Music Industry Background}

Professional music artists earn revenues principally from recorded music sales and from live performances. $^{3}$ Recorded music is produced under contract with a record label: the artist records an album as a work-for-hire, and the record label markets and distributes the album. Typical production costs during this period are in the neighborhood of $\$ 100,000-\$ 250,000$, and industry executives report that marketing and distribution costs during this period often eclipsed the cost of production. The standard contract is a royalty contract: the artist is paid royalties on album sales, and receives an advance against those royalties in order to cover living expenses and studio costs during the production of the album. Royalty rates range between $10-18 \%$ of retail, with the typical rate being $12 \%$; however, artists earn somewhat less than this due to various deductions that are usually built into the contract. For the time period we study, a reasonable estimate is that the artist earns around $\$ 1.00$ for every CD she sells. ${ }^{4}$ Record labels during this period hold a negligible stake in the live performance

\footnotetext{
${ }^{3}$ Some very successful songwriters also earn significant revenues from music publishing fees, and some star artists have substantial income from endorsements, but the typical artist relies mostly on recorded music sales and concerts.

${ }^{4}$ Instead of using a standard royalty contract, some artists negotiate "penny contracts" specifying artist payments as a fixed dollar amount per CD sold. The typical artist share in these contracts is reportedly $\$ 1.25$ per CD; however, artists who negotiate such contracts have more bargaining power than the average artist.
} 
business. Although labels usually offered some nominal touring support to new artists as part of the recording contract, and sometimes coordinated with concert promoters to advertise a show, they do not take a share of the touring revenues. ${ }^{5}$ More recently, these contracts have begun to change, so that recording labels contract explicitly over some share of the artist's touring receipts.

Artists' live performances are coordinated and underwritten by concert promoters. The promoter finances almost every aspect of the concert production, including renting the venue, paying the artist and staff, and advertising. Artists are paid as a percentage of ticket revenues, subject to some minimum (called the "guarantee"). Artists also make money from merchandise sales; for some artists this can be a significant component of the net earnings. A typical deal gives $70-80 \%$ of merchandise revenues and $70-85 \%$ of the gross ticket revenues to the artist, although the actual percentages may be somewhat lower because various deductions are made to the gross ticket revenues before the artist's cut is taken.

Although artists have virtually no say in the pricing of recorded music, most industry sources identify the artist as the primary agent with responsibility for setting concert ticket prices. The artist and/or artist's manager sets prices in consultation with the promoter and venue owner. The parties can have conflicting incentives; for example, aside from the rental fee for the venue, the venue owner's revenue comes primarily from concessions and parking, so they tend to push for low ticket prices in order to fill the house.

In May of 1999, the software program Napster introduced an easy-to-use interface by which consumers could share and download digital copies of songs. Napster and similar programs represented a dramatic shift in the distribution technology for recorded music. ${ }^{6}$ Napster gained currency quickly, with a reported user base of over 20 million unique accounts at its peak and over a half million unique IP addresses connected at any given time on a routine

\footnotetext{
${ }^{5}$ Tour support is typically a recoupable expense, but it is recouped from recorded music revenues. This convention may be a holdover from an earlier era: historically, labels subsidized concert tours only as a way of promoting albums, and concerts were often not expected to be profitable on their own.

${ }^{6}$ Although earlier technologies also allowed for illegitimate reproduction (e.g. cassette tapes are easily copied), they were much more limited in scope, and typically had greater quality degradation.
} 
basis. ${ }^{7}$ The Recording Industry Association of America (RIAA) claimed that the presence of Napster eroded sales of CDs by facilitating copyright violations, and sued to have Napster dismantled in December of 1999. In 2003, the RIAA began suing individual participants of file sharing networks, and subsequent activity on these networks was reported to have declined. $^{8}$

\subsection{Data}

The data we use in this study come from several sources. The data on concerts come from Pollstar, a company that tracks virtually all concert activity in the United States. The data describe 227,230 concert events performed by 12,356 artists in the period 1993-2004. For concerts performed between 1993-2002, the data provide detailed box office information, including tickets sold, total ticket revenues, and high and low ticket prices. For 2003 and 2004, we observe the dates, locations (city and venue name), and identities of all performing bands, but we do not have data on box office receipts. Although data for years past 2004 are obtainable, we truncate at 2004 because the company implemented a significant change to its reporting mechanism in 2005 that makes later years' data difficult to compare with the period in which we are primarily interested (i.e., the years around 1999).

The dramatic increase in concert activity shown in Figure 1 is based on Pollstar data. Given the change in reporting in 2005 (and consequent change in coverage), one might worry that

\footnotetext{
${ }^{7}$ Original source: CNNMoney 2000. For an excellent review of the industry and the timing of filesharing events specifically, see Blackburn (2004).

${ }^{8}$ The Supreme Court ruling in MGM v. Grokster in June 2005 represented a significant legal victory for the RIAA, as the court held that distributors of file-sharing software could be held secondarily liable for copyright infringements facilitated by their software, essentially allowing the RIAA to go beyond merely suing individuals who shared files illegally to suing the companies whose software enables the sharing. In addition to the legal front, the music industry has also battled file-sharing on the technological front, using various encryption and digital rights management technologies to curb the flow of illegal music downloads. Park and Scotchmer (2004) analyze the impact of such technologies on the pricing of digital goods. Legal channels of digital music distribution are, by now, becoming well established. Most notably, iTunes launched in October, 2003.
} 
the increase in concert events after 2000 also reflects a change in data coverage rather than a change in actual concert activity. To address this concern, we conducted an extensive audit of the Pollstar data during the years of 1996-2002 for concerts in the Boston area using a local weekly newspaper that has a reputation as the best guide for music in the area. Pollstar did not have complete coverage of all events (particularly events at small venues). The coverage rate increased slightly over time, but the increase was gradual. In particular, there was no evidence that the coverage rate increased sharply after $2000 .^{9}$ In 2005 , Pollstar made changes that did lead to a dramatic increase in coverage. We do not report data from 2005 onward because we do not feel it is comparable to the data used in the rest of our analyses.

Our data on album sales come from Nielsen SoundScan, a company that tracks music sales at the point of sale. ${ }^{10}$ Some of the results we report below are based on aggregate sales by DMA (designated market area), covering the years 1993-2002. ${ }^{11}$ We also observe highly disaggregated data for a subsample of 1,806 artists who we can match to the concert data from Pollstar. We refer to these artists as our "matched sample." For these artists we observe weekly CD sales by DMA at the individual album level; for the analyses in this paper, we summarize over the artists' albums and simply examine total album sales by artist/DMA/week. The matched sample may not be perfectly representative of the broader universe of artists, and we discuss sample selection issues in Section 4 along with running concert analyses both on the matched sample and the full Pollstar data.

We collect additional data on recorded music for individual albums from MusicBrainz, which is an online database that tracks detailed album information for official album releases for the purpose of documenting or "tagging" downloaded music tracks. ${ }^{12}$ The MusicBrainz

\footnotetext{
${ }^{9}$ The local weekly newspaper used for the audit was The Boston Phoenix. Details of the audit are available from the authors upon request.

${ }^{10}$ For our sample period, SoundScan's coverage rate was reported to be approximately $80 \%$ of all music sales.

${ }^{11}$ A DMA is similar to an MSA.

${ }^{12}$ The MusicBrainz database is used by a wide range of complementary "tagging" software programs, and is widely cited in the music community as a reliable source of information on recorded songs and albums.
} 
database has extensive coverage of recorded music releases, tracking 240,000 albums from 100,000 artists, and provides information on the date of release, length and title of each song, album credits, and so on. The data from MusicBrainz are useful for documenting the timing of album releases, and also for characterizing the population of recorded releases over time. $^{13}$

In addition to the detailed data on concerts and recorded music, we supplement our analyses with a number of characteristics about artists and recorded releases that are collected from several other sources. We use artist characteristics from allmusic.com's online database of artists, and data from Recorded Industry Association of America (RIAA) to measure cumulative album sales prior to 1993 for artists that were established before that date. We also use data from BigChampagne (collected during 2007) to measure a cross-section of downloading activity across artists and cities. ${ }^{14}$

\section{Aggregate trends}

Since file-sharing technologies made millions of songs freely downloadable over the internet, they were naturally expected to displace legal sales. Most empirical studies have found evidence of this displacement. However, while file-sharing decreased legal sales, it almost certainly increased the overall consumption of recorded music. Evidence from time-use surveys indicates a dramatic increase in music listening between 1998 and 2001. In one survey, respondents in 2001 reported spending 3 times as much time listening to music as respondents from 1998. More tellingly, among respondents who reported having below-median internet usage rates, the increase in music listening was negligible (just over 10\%), whereas the increase for those with above-median internet usage was more then tenfold. ${ }^{15}$ Since recorded music and live performances are complementary, an increase in the consumption of recorded

\footnotetext{
${ }^{13}$ This allows for a comparison of our matched sample to the population of releases over time.

${ }^{14}$ We cite these additional sources and provide additional detail throughout the analyses as appropriate.

${ }^{15}$ Based on internet-accessible data from National Time Diary Studies conducted by the Survey Research Center at the University of Maryland: see http://www.popcenter.umd.edu/sdaweb/diary9801/Doc/Diar.htm.
} 
music should increase the demand for concerts: the more people who are listening to an artist's music, the larger is the market for a concert by that artist.

In addition to this demand-side effect, file-sharing may also have shifted artists' incentives on the supply side. To the extent that file-sharing eroded the profitability of selling recorded music, artists had an incentive to reallocate effort away from recording new albums, instead performing more frequent and/or more extensive concert tours.

As a first step in documenting the empirical relevance of these effects, in this section we describe aggregate trends in concert activity and music sales in the years before and after file-sharing technologies became pervasive. Time trends alone cannot establish any causal link; our purpose in this section is simply to examine whether the patterns of change within the music industry are consistent with the anticipated effects of file-sharing.

\subsection{Live performances}

Figure 5 documents the sharp increase in the number of live performances after the year 2000. Table 1 provides more detail on trends in live performances between 1995-2004. ${ }^{16}$ The first column reports the number of concerts, and matches figure 5. The second column reports the number of artists on tour, which also increases sharply after 2000. The number of concerts per artist is reported in the third column. This number is falling before 2000, and then rising in 2001-02 and and falling again in 2003-04. We suspect that the entry of many new artists, especially in 2003-04, means that the marginal artist on tour performs fewer concerts in those years. The number of cities in which an artist tours falls from 1995-1999, and then levels off. The percentage of concerts performed in the 20 largest cities in the US is relatively stable over time. The number of tickets per concert rises from 1995-2000, and then falls. Combined with the first column, this suggests a trend toward a larger number of smaller concerts. Note that the fall in the number of tickets per concert is smaller than the

\footnotetext{
${ }^{16}$ As noted earlier, we focus on the time periods 1995 to 2002 or 1995 to 2004 depending on availability of the relevant variables. Including data for ealier years (e.g., 1993 and 1994) does not impact the general implications of the analyses and is not feasible for the analyses in Section 4.
} 
rise in the number of concerts performed. Thus, total ticket sales increased over the period.

The table also shows that average ticket prices rose steadily (especially after 1999). Since both prices and quantities (total ticket sales) increased, the changes in this industry can not be solely attributed to a shift in supply. Demand must have increased for these patterns to hold.

In addition to changes over time, we also observe cross-sectional variation in concert performances over time across cities. The top panel of Table 2 reports average annual growth rates in concert performances for the 1996-1998 and 2000-2002 periods for different types of cities over time. We classify cities based on two different measures of the likely importance of filesharing. In the first classification, we designate a DMA as "low (high) broadband" if its broadband penetration is below (above) the median. Second, we classify cities into high- and low-download markets based on whether a city's downloading activity was disproportionately high or low relative to population, based on the BigChampagne data from $2007 .^{17}$

Growth in concert performances accelerated sharply for both high- and low-broadband markets in the post-Napster period, and the acceleration was significanly more pronounced in the high-broadband markets. A similar pattern holds for the high- vs. low-download classification. While we do not know how accurately these groupings proxy for actual file-sharing, the patterns in the table are at least consistent with our hypothesis that increases in concert activity were driven partly by the arrival of file-sharing.

\subsection{Recorded music}

The bottom panel of Table 2 shows analogous comparisons for growth rates in album sales. Annual sales were growing at double-digit rates in the years just before file-sharing, but began shrinking after file-sharing. In contrast to concert performances, however, the trends

\footnotetext{
${ }^{17}$ Specifically, we regress the log of total downloads (by city) on population rank, and then classify cities based on the residuals. (Cities with residuals above the median are the "high-download" cities.)
} 
were essentially the same in high- and low-broadband markets (and high- and low-download markets). Thus, sales declines were not more pronounced in the markets that one might associate with greater file-sharing activity. This could reflect the coarseness of our proxies for file-sharing and the difficulty of measuring the degree of sales displacement that results from file-sharing. (The studies that have found convincing evidence of a displacement effect have used individual-level data, not market-level comparisons.)

Regardless of its cause, the decline in album sales after 1999 may have reduced artists' incentives to produce recorded music, and the apparent increase in demand for concerts would have further pushed artists to reallocate effort away from recording albums toward performing concerts. One of the empirical implications of this reallocation would be an increased lag between album releases. Table 3 reports trends in the time between album releases, based on the MusicBrainz database. The table reports a backward-looking measure (time since last release); the patterns are similar if we use a forward-looking measure (time until next release). The lag between album releases increased after 1999, primarily because more artists took 3 or more years between album releases. However, there is no obvious break in trend around 1999-2000. The trend toward longer lags appears in the 1995-1999 period as well.

While Table 3 examines the album production of existing artists, file-sharing may also have affected the entry of new artists. This effect is more subtle, however. To the extent that file-sharing reduced the profitability of recorded music, we could expect record labels to sign fewer artists and release fewer albums. On the other hand, if touring became more profitable because of the greater accessibility of recorded music to potential listeners, more artists may have been able to profitably exist, and also to release CDs. ${ }^{18}$ Table 4 documents the entry of new artists and new albums over time, again based on the MusicBrainz database. Both series increase over time; neither exhibits any sharp breaks in trend.

\footnotetext{
${ }^{18}$ Relatedly, if digital technology lowers the cost of producing recorded music, we may also get greater entry into the market for recorded goods in spite of the potential for file-sharing to have some displacement effect.
} 


\section{Artist-level analyses}

The impact of file-sharing on concerts and album sales may differ substantially between large and small artists. File-sharing may increase awareness of smaller, more obscure artists and their music by making the music available from more sources and at a much lower cost (or for free in the case of illegal file-sharing). Broader awareness of these artists should be reflected in increased demand for their concert performances. Similarly, while file-sharing may off-set some album sales for small artists this may be mitigated in part by increased sales from the larger potential fan base that may result from increased awareness of those artists. On the other hand, file-sharing may have a relatively small impact on the awareness of music for large, "superstar" artists. The music for these artists was already widely played prior to file-sharing, and thus file-sharing may have had little impact on concert demand for these top performers. Similarly, file-sharing is likely to primarily displace album sales for large bands with little or no compensating increase from a potentially larger fan base. In summary, we expect small bands to experience a greater increase in concert revenues and less of a decline in album sales than large, highly popular bands following the entry of Napster.

\subsection{Defining variables of interest}

A key challenge to undertaking artist-level analyses in concert and album data is appropriately defining the level of observation to track empirically. This challenge is common to analyzing markets for information goods generally. Demand for many information goods peaks at or near the release date, and then decays rapidly (e.g., movies and music), and production occurs in discrete jumps (e.g., the release of a new movie or album). In the music industry, these types of dynamic considerations are important for any given artist or band. Over time, an artist will create and release new songs and albums, spend time touring, and experience life-cycle effects (both in their own costs of effort and in the de-

mographic background of their fan base). The nature of these dynamic effects makes any analysis of individual artists fraught with difficulty, as dynamic considerations often swamp 
other industry-level effects of interest.

We address this challenge by defining an observation as a year-rank pair. For example, to track concert revenues over time we rank artists based on their aggregate concert revenues in each year. Rather than analyze changes in a particular artist's concert revenues over time (which can vary dramatically from year-to-year), we analyze changes in revenues at the rank-level over time (i.e., changes in concert revenues for the 10th-highest grossing artist in each year). Patterns based on the concert revenue rank observations are much more stable over time than revenues for a given artist, and allow us to analyze the impact of file-sharing without the noise of dramatic changes over time in content release, concert tour schedules, and life-cycle effects that plague artist-specific data. Therefore, we analyze how file-sharing impacts concert revenues for the 50 highest-grossing artists in each year compared to the 201st to 300th highest-grossing artists.

To analyze the impact of file-sharing on a consistent basis for both concerts and album sales, we create a matched sample for the 1,806 artists for whom we have detailed album sales and concert revenue information. All concert-based analyses are carried out for the same set of artists used to analyze album sales. We also implement the concert-based analyses on the full Pollstar concert data to ensure that any findings based on the matched sample are also consistent with the population of concerts more generally. The concert revenue findings based on the matched sample and the full Pollstar data have very similar implications, suggesting that our findings for the matched sample are representative of all artists more broadly.

Our main outcome variables of interest are growth rates for concert revenue and album sales, and we analyze these outcomes separately at three levels: (1) the national level, (2) specific DMAs (i.e., New York, Los Angeles, Chicago, and all other DMAs combined), and (3) groups of DMAs based on broadband internet penetration in 1999. At the national level, we calculate growth rates for concert revenues by aggregating annual concert revenues to the national level and ranking each artist based on his aggregate concert revenues in that year. Using these individual year-rank observations, we calculate a growth rate as the difference between the log of concert revenues in the current and preceding years for artists of the same 
rank. We repeat the exercise using album sales.

Artists are also assigned to cohorts based on their aggregate national concert revenues. We create identifier variables for each cohort group (e.g., for the matched concert revenue data, cohort 1 reflects nationally ranked artists 1 to 50, cohort 2 is 51 to 100, and so on). We use only year-rank observations of 409 or better because that is the lowest rank for which we maintain a balanced sample from 1995 to $2002 .{ }^{19}$ Finally, we calculate a dummy variable to identify years following the entry of Napster (i.e., 2000 to 2002) and interact this variable with our cohort groups.

Analyses conducted for specific DMAs or for groups of DMAs we refer to as "regional level" analyses. For these analyses, the growth rates are calculated based on the artists' regional ranks (rather than the national ranks) in the corresponding region of analysis. For example, when we analyze album sales for the New York DMA, we rank artists based on their aggregate album sales in just the New York DMA and calculate album sales growth rates based on the change in the log of current album sales for a given New York DMA-ranked artist. ${ }^{20}$ While growth rates are calculated at the regional level, artists continue to be assigned to cohorts based on their national aggregate concert revenues or album sales. Calculating growth rates based on ranks that correspond to the region of analysis, but assigning cohort groups based on national outcomes addresses two issues. First, using the rank for the region of analysis to calculate growth rates ensures that growth rates are based on artists who have a similar level of popularity in a given region (i.e., the 10th-ranked artist in the region this year compared to the 10th-ranked artist in the region last year) and results in smoother and more reasonable

\footnotetext{
${ }^{19}$ There are 409 artists with positive concert revenues in 1993 in our matched sample, and this count of artists increases for every year following 1993. Similarly, there are 703 artists with album sales in 1993 in our matched sample, and this count of artists also increases for every year following 1993. To ensure that annual concert revenues (album sales) are not overly impacted by the growth in the number of artists performing (recording) during the course of the year we drop 1993 from the analyses. Using the remaining data we can then calculate growth rates for concert revenues (album sale) starting in 1995.

${ }^{20}$ When several DMAs are represented in a given region, we aggregate concert revenues and album sales for each artist across all of the DMAs in that region, and then calculate ranks and growth rates based on those regionally aggregated data.
} 
growth rates. Second, relying on the national ranks to assign artists to cohorts ensures that the cohorts and their corresponding coefficients are comparable across analyses. ${ }^{21}$

In all analyses the cohort 1 indicator and the interaction of the Napster and cohort 1 indicators are excluded from the analyses. The constant term captures the average growth rate for cohort 1 for the pre-Napster period, while the Napster term captures the relative change in cohort 1's growth rate for the post-Napster period compared to the pre-Napster period. The cohort 2 and higher indicators capture the difference between the individual cohort pre-Napster growth rates and the cohort 1 growth rate; while the Napster and cohort 2 and higher interaction terms capture the relative change between pre- and post-Napster growth rates for that cohort compared to the change in growth rate for cohort 1.

\subsection{National and DMA-Level Analyses}

Table 5 reports results of analyses on concert revenue growth rates for the matched concert and album sales sample of artists. The column labeled "National" reports the regression results of concert revenue growth on cohort identifiers, and cohort identifiers interacted with the post-Napster identifier. Consistent with file sharing having a larger impact on concert demand for smaller, more obscure artists than for larger, better-known artists, we find no positive impact of Napster on the concert revenue growth rate for the largest artist cohort, but substantially higher concert growth rates following entry of Napster for smaller artists. The results for the largest artists (cohort 1, rank 1 to 50) are captured by the constant term for the period 1995 to 1999 (0.12), and the Napster term captures the difference between the growth rate for cohort 1 in the 2000 to 2002 period compared to the 1995 to 1999 period $(-0.05)$. The results indicate that the concert revenue growth rate for artists in cohort 1 had a statistically significant decline following entry of Napster. However, the next largest group of artists (cohort 2) experienced a significantly higher growth rate following Napster. The Napster-cohort 2 interaction term compares the change in the growth rate for cohort 2 before

\footnotetext{
${ }^{21}$ For example, it may not be appropriate to compare the top ranked concert in the Albuquerque DMA to the top ranked concert in the New York DMA.
} 
and after Napster to the change in the growth rate for cohort 1 before and after Napster, and the coefficient of 0.12 indicates that cohort 2 experienced a significantly more positive impact on its concert revenue growth rate following Napster than cohort 1. Furthermore, the relative growth rate in concert revenue post Napster is successively larger for the lower ranked artist cohorts: 0.17 for cohort 3, 0.21 for cohort 4, and 0.23 for cohort 5 . These results indicate that concert revenues for small artists grew substantially faster following entry of Napster, and that this increase in growth rate for small artists was significantly more positive than the change in concert revenue growth rates for superstar artists following entry of Napster.

Table 5 also reports results at the DMA level separately for the three largest DMAs and for all other DMAs combined. ${ }^{22}$ While the results of the analyses for New York, Los Angeles, Chicago, and all other DMAs differ somewhat in terms of the levels of the coefficients, they are consistent in terms of the overall implications. In every region, the concert revenue growth rate for cohort 1 (the largest artists) declines following entry of Napster although the decline is not statistically significant for New York, Los Angeles, and Chicago. On the other hand, the concert revenue growth rates for smaller artists increase significantly following entry of Napster. Table 6 reports the corresponding results using the full Pollstar sample of artists. The implications of the results using the full Pollstar data are almost identical to those using the matched sample.

Table 7 reports results for the album sales analyses. These analyses are constructed in a comparable manner as those for concert revenues in Table 5, but artists are instead ranked based on album sales and growth rates are calculated using album sales. Again, results at the national and DMA level are extremely consistent. Virtually all artist cohorts experience a decline in album sales following entry of Napster, which is consistent with the findings in prior papers. However, the largest artists (cohort 1) experience by far the most severe

\footnotetext{
${ }^{22}$ Calculating growth rates at the DMA level works well for large DMAs. However, smaller DMAs often have fewer concerts in a given year and greater variance in the quality of concerts from year-to-year. Calculating concert revenue growth rates for smaller DMAs can therefore introduce substantial noise into the analysis.
} 
decrease in album sales. In the national level analyses, the coefficient on the Napster variable is -0.17 and indicates a significantly lower album sale growth rate for cohort 1 following entry of Napster compared to before Napster (when the growth rate was 0.07). All of the smaller artist cohorts also experienced lower growth rates following Napster; however, the effect is far more muted for the smaller artists. Cohorts 2 through 8 all have positive (and except for cohort 8, statistically significant) Napster interaction coefficients, indicating that the decline in album sales growth rates for cohorts 2 through 8 was significantly less than for cohort 1 following Napster. Similar to the results based on concert revenue growth rates, the results using album sales growth rates are also consistent with file sharing increasing awareness of smaller artists and potentially having a positive impact on demand for small artists' concerts and albums. This is consistent with the hypothesis that the positive demand implications of file sharing should be much stronger for small, more obscure artists than for larger, betterknown artists. Results for the New York, Los Angeles, Chicago, and all other DMAs are very consistent with the national results.

\subsection{Broadband Penetration Level Analyses}

As a final sensitivity analysis, we investigated whether the results differ depending on the level of broadband penetration. Rather than segment the analyses for the three largest DMAs as in the previous set of analyses, we segmented the DMAs based on quartiles for broadband penetration (as measured in 1999). Tables 8 and 9 report the results for concert revenues for the matched sample of artists and the full Pollstar data respectively, and Table 10 reports the results for album sales. If broadband penetration is a good proxy for the incidence of file-sharing, one would expect to find that the impact of file sharing on concert revenues and album sales was more pronounced for DMAs with greater broadband penetration. Instead, the results appear to be quite similar across all of the quartiles for broadband penetration and similar to the national results. One possible explanation for this finding is that our measure of broadband penetration covers each DMA as a whole. Ideally, one would like a measure of broadband penetration for that demographic in each DMA that are most likely 
to attend concerts and purchase albums. Unfortunately, such a measure is not available. A further complicating factor is that the sub-population that most frequently attends concerts and purchases albums may be early to adopt broadband access regardless of their DMA (e.g., college students). Finally, variation in broadband penetration across DMAs for the relevant sub-population that attends concerts and purchases albums may be quite small. If this is in fact the case, then we would expect to find little difference in the impact of file-sharing across DMAs on concert revenue or album sales.

\section{Discussion and Conclusion}

We find evidence consistent with illegitimate redistribution of digital goods increasing revenue from non-digital complementary products. As with the earlier literature, we find that sales of recorded music declined precipitously with the entry of Napster and large-scale filesharing. While file-sharing may have substantially displaced album sales, it also facilitated a broader distribution of music, which appears to have expanded awareness of smaller artists and increased demand for their live concert performances. Concert revenues for large artists, however, appear to have been largely unaffected by file-sharing. Music for large artists was likely widely available prior to file-sharing, and as a result it is not surprising that demand for those artists' concerts would have been largely unaffected by file-sharing. Similarly, the decline in album sales is much more pronounced for large artists than for small artists. Again, for small artists, file-sharing may have increased awareness of their music and encouraged some additional album sales from a larger fan base even as it displaced album sales to others.

While our findings are consistent with file-sharing affecting concert revenues and album sales, we cannot entirely rule out the influence of other contemporaneous changes in the music industry. During the time period of our analysis, the concert promotion industry became increasingly concentrated, with Clear Channel Entertainment (now Live Nation) gaining an increasingly large share of concert promotion activities. At the same time, Clear Channel was also expanding the breadth of radio stations under its control. Finally, digitization not only 
affected the reproduction and redistribution of recorded music, but also changed production technologies more generally. While all of these factors could have influenced growth rates for concert revenues and album sales, we would expect their influence to have been more gradual and more consistent across large and small artists than what we observe in the data. Given the dramatic changes that we observe over a very short period of time around the entry of Napster, and the varying impacts for large and small artists, the findings in this paper appear to be most consistent with the result of file-sharing and not other contemporaneous factors.

More generally, increased digitization of information and entertainment content over the past decade, along with dramatic technological changes in the reproduction and redistribution of such goods, has raised substantial concerns with respect to the future viability of many information and entertainment goods markets. Recorded music, newspapers, and magazines have all undergone radical changes through on-line distribution and pricing that have either facilitated illegitimate redistribution of their content or generally increased the availability of legitimate but free content. Markets for television, books and movies have just recently started to embrace digital distribution channels, but have also faced challenges from free and/or illegitimate distribution of their content (e.g., YouTube). Finally, software has long fought against illegal copying and is also taking some steps toward free legitimate distribution through "cloud" computing rather than personal licensing. These changes are undoubtedly having profound impacts on the market structure of these industries, making it more difficult to generate revenue from traditional sources but also greatly expanding overall distribution and availability of content. To the extent that content in these industries becomes available to a larger potential customer base, some of the decline in revenue from traditional sources may be offset by increased demand for complementary products. 


\section{References}

Blackburn, D., "Online Piracy and Recorded Music Sales," mimeo, (Dec 2004).

"Digital Millennium Copyright Act," Public Law 105-304, (Oct 1998).

Hong, SH., "Measuring the Effect of Digital Technology on the Sales of Copyrighted Goods: Evidence from Napster," mimeo, (Jan 2007).

Liebowitz, S., "Copying and Indirect Appropriability," Journal of Political Economy, 91(5), pp. 945-957 (Oct 1985).

Liebowitz, S., "Will MP3 Downloads Annihilate the Record Industry? The Evidence So Far," in Advances in the Study of Entrepreneurship, Innovation and Economic Growth, ed. Libecap, G., V.15, pp. 229-260 (2004).

"Metro-Goldwyn-Meyer Studios Inc, et al v. Grokster, Ltd, et al.," United States Supreme Court, 545 U.S. 913 (2005).

Oberholzer-Gee, F. and K. Strumpf, "The Effect of File Sharing on Record Sales: An Empirical Analysis," Journal of Political Economy, 115(1), pp. 1-42 (Jan 2004).

Park, Y. and S. Scotchmer, "Digital Rights Management and the Pricing of Digital Products," mimeo, (Sep 2004).

Rob, R. and J. Waldfogel, "Priacy on the Silver Screen," Journal of Industrial Economics, 55(3), pp.379-395 (Sep 2007).

Teece, D., "Profiting from Technological Innovation: Implications for Integration, Collaboration, Licensing, and Public Policy," Research Policy, 15(6), pp. 285-305 (1986).

"Uniform Computer Information Transaction Act," passed in Maryland (2000), and Virginia (2000), (Oct 1998).

Zentner, A., "Measuring the Effect of File Sharing on Music Purchases," Journal of Law E Economics, 49(1), pp. 63-90 (2006). 
Figure 1: Album Sales and Concerts, 1995-2004

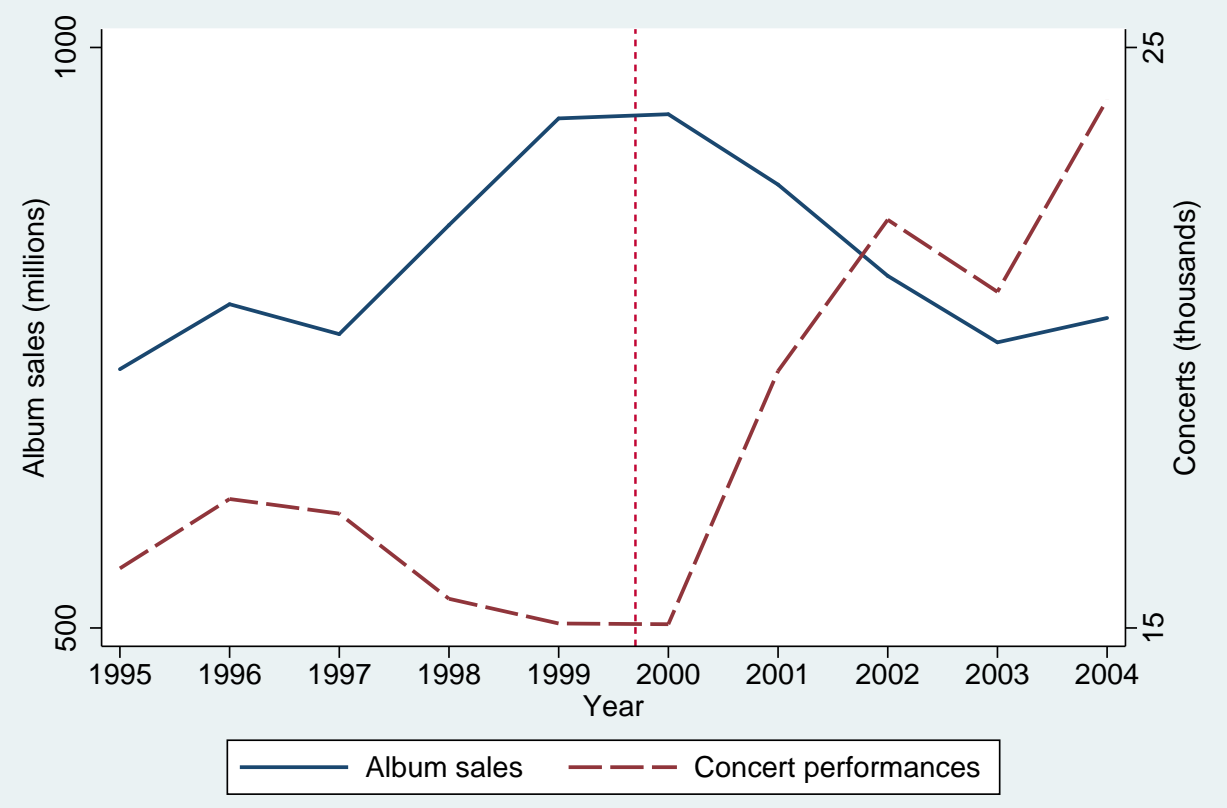


Table 1: Concerts: changes over time

\begin{tabular}{cccccccc}
\hline \hline Year & $\begin{array}{c}\text { Number of } \\
\text { Concerts }\end{array}$ & $\begin{array}{c}\text { Number of } \\
\text { Artists on Tour }\end{array}$ & $\begin{array}{c}\text { Concerts per } \\
\text { Artist }\end{array}$ & $\begin{array}{c}\text { Cities per } \\
\text { Artist }\end{array}$ & $\begin{array}{c}\text { \% in largest } \\
\text { 20 DMAs }\end{array}$ & $\begin{array}{c}\text { Tickets per } \\
\text { concert }\end{array}$ & $\begin{array}{c}\text { Average } \\
\text { price }\end{array}$ \\
\hline 1995 & 16,027 & 2,159 & 7.42 & 15.66 & 58.86 & $2,841.03$ & 26.32 \\
1996 & 17,222 & 2,309 & 7.46 & 15.88 & 57.37 & $2,872.94$ & 25.38 \\
1997 & 16,971 & 2,348 & 7.23 & 15.38 & 56.78 & $2,923.35$ & 27.84 \\
1998 & 15,503 & 2,361 & 6.57 & 14.49 & 58.08 & $3,128.90$ & 29.31 \\
1999 & 15,077 & 2,297 & 6.56 & 13.99 & 60.53 & $3,246.29$ & 33.24 \\
2000 & 15,065 & 2,309 & 6.52 & 14.35 & 61.18 & $3,293.64$ & 35.52 \\
2001 & 19,425 & 2,894 & 6.71 & 13.85 & 60.91 & $2,708.98$ & 35.26 \\
2002 & 22,033 & 3,292 & 6.69 & 14.25 & 64.03 & $2,459.34$ & 36.02 \\
2003 & 20,791 & 3,683 & 5.65 & 14.26 & 59.99 & - & - \\
2004 & 24,103 & 4,212 & 5.72 & 14.68 & 58.37 & - & - \\
\hline \hline
\end{tabular}

Based on Pollstar data. Cities per artist is the average number of different major markets (DMAs) artists performed in, conditional on performing at least one concert. Prices in the last column are deflated to 1999 dollars using the CPI. 
Table 2: Average annual growth: concert performances and album sales

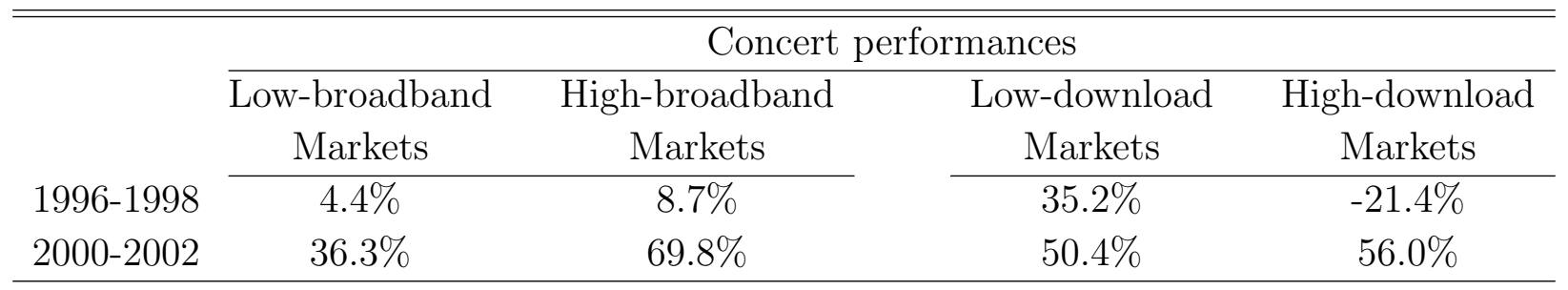

Album sales

\begin{tabular}{|c|c|c|c|c|}
\hline & $\begin{array}{c}\text { Low-broadband } \\
\text { Markets }\end{array}$ & $\begin{array}{c}\text { High-broadband } \\
\text { Markets }\end{array}$ & $\begin{array}{c}\text { Low-download } \\
\text { Markets }\end{array}$ & $\begin{array}{c}\text { High-download } \\
\text { Markets }\end{array}$ \\
\hline 1996-1998 & $20.2 \%$ & $19.0 \%$ & $21.2 \%$ & $18.0 \%$ \\
\hline 2000-2002 & $-16.5 \%$ & $-15.0 \%$ & $-16.1 \%$ & $-15.4 \%$ \\
\hline
\end{tabular}

Cells report averages (across DMAs) of the annual percentage growth rate for the designated time period. Low vs. high broadband distinction is based on Forrester Research broadband penetration measure (percent of households with broadband internet in 1999). Low vs. high download distinction is based on BigChampagne data; see text for explanation. 
Table 3: Time between album releases

\begin{tabular}{cccc}
\hline \hline Albums & \multicolumn{3}{c}{ Years since last release } \\
\cline { 2 - 4 } released in: & $0-1$ & 2 & $3+$ \\
\hline 1995 & 59.60 & 20.09 & 20.31 \\
1996 & 56.39 & 21.35 & 22.26 \\
1997 & 56.38 & 21.18 & 22.44 \\
1998 & 54.38 & 22.17 & 23.45 \\
1999 & 55.36 & 20.58 & 24.06 \\
2000 & 54.39 & 20.20 & 25.41 \\
2001 & 53.23 & 20.32 & 26.46 \\
2002 & 51.38 & 21.47 & 27.15 \\
2003 & 50.75 & 21.05 & 28.21 \\
2004 & 50.09 & 21.01 & 28.90 \\
\hline
\end{tabular}

Times between releases calculated from MusicBrainz database. Cells report the percentage of albums that fall in each category in each pair of year based on the number of calendar years elapsed since the artist's previous album release. (Debut albums are excluded.) 
Table 4: Recorded music: changes over time

\begin{tabular}{cccc}
\hline \hline Year & $\begin{array}{c}\text { Unit sales } \\
\text { (millions) }\end{array}$ & $\begin{array}{c}\text { Number of } \\
\text { new artists }\end{array}$ & $\begin{array}{c}\text { Number of } \\
\text { new albums }\end{array}$ \\
\hline 1995 & 722.9 & 3,822 & 7,576 \\
1996 & 778.9 & 4,093 & 7,855 \\
1997 & 753.1 & 4,216 & 8,642 \\
1998 & 847.0 & 4,755 & 9,196 \\
1999 & 938.9 & 5,472 & 10,344 \\
2000 & 942.5 & 5,883 & 11,198 \\
2001 & 881.9 & 5,920 & 11,819 \\
2002 & 803.3 & 6,005 & 12,925 \\
2003 & 746.0 & 6,851 & 14,153 \\
2004 & 767.0 & 7,931 & 15,941 \\
\hline \hline
\end{tabular}

Sales figures in the first two columns are from RIAA, and include digital sales from ???? on. Revenues are deflated to 1999 dollars using the CPI. The second column reports the number of new artists (i.e., artists releasing debut albums) each year, based on the MusicBrainz database. The third column reports the number of new albums released (by all artists) each year, also based on the MusicBrainz database. 
Table 5: Concert Revenue Growth Rate - Matched Sample of Artists

\begin{tabular}{l|c|cccc}
\hline \hline & & \multicolumn{4}{|c}{ DMA Level } \\
& National & NY & LA & Chicago & Other \\
\hline Cohort 2 (rank 51 to 100) & -0.05 & 0.00 & 0.05 & -0.04 & -0.06 \\
& {$[-2.28]$} & {$[-0.18]$} & {$[1.20]$} & {$[-1.39]$} & {$[-2.47]$} \\
Cohort 3 (rank 101 to 200) & -0.04 & 0.01 & -0.02 & -0.07 & -0.04 \\
& {$[-2.63]$} & {$[0.38]$} & {$[-0.58]$} & {$[-2.61]$} & {$[-2.25]$} \\
Cohort 4 (rank 201 to 300) & -0.03 & 0.02 & -0.04 & 0.03 & -0.03 \\
& {$[-1.60]$} & {$[0.49]$} & {$[-0.76]$} & {$[0.82]$} & {$[-1.49]$} \\
Cohort 5 (rank 301 to 409) & 0.03 & 0.01 & -0.05 & -0.01 & 0.03 \\
Napster & {$[1.94]$} & {$[0.24]$} & {$[-1.04]$} & {$[-0.21]$} & {$[1.49]$} \\
Napster * Cohort 2 & -0.05 & -0.01 & -0.02 & -0.01 & -0.07 \\
Napster * Cohort 3 & {$[-2.15]$} & {$[-0.33]$} & {$[-0.63]$} & {$[-0.29]$} & {$[-2.80]$} \\
Napster * Cohort 4 & 0.12 & 0.12 & 0.18 & 0.10 & 0.13 \\
& {$[3.93]$} & {$[2.47]$} & {$[2.88]$} & {$[2.30]$} & {$[4.27]$} \\
Napster * Cohort 5 & 0.17 & 0.22 & 0.37 & 0.22 & 0.17 \\
Constant & {$[6.50]$} & {$[3.68]$} & {$[5.78]$} & {$[4.66]$} & {$[6.41]$} \\
& 0.21 & 0.25 & 0.61 & 0.25 & 0.21 \\
Obs & {$[7.65]$} & {$[3.00]$} & {$[8.38]$} & {$[3.76]$} & {$[7.96]$} \\
R-squared & 0.23 & 0.36 & 0.64 & 0.23 & 0.23 \\
\hline \hline
\end{tabular}

t-stats are reported in brackets and are calculated using robust standard errors. Analyses rely on the matched artist sample for concerts and albums. The concert revenue growth rate is calculated as the log of current year concert revenues minus the log of previous year concert revenues for the same revenue rank artist in both years based on revenues in the region of analysis. Cohorts are based on national concert revenue ranks for all analyses. 
Table 6: Concert Revenue Growth Rate - Pollstar Dataset

\begin{tabular}{l|c|cccc}
\hline \hline & & \multicolumn{4}{|c}{ DMA Level } \\
& National & NY & LA & Chicago & Other \\
\hline Cohort 2 (rank 101 to 300) & -0.01 & 0.01 & 0.08 & 0.01 & -0.01 \\
& {$[-1.58]$} & {$[0.86]$} & {$[3.77]$} & {$[0.70]$} & {$[-1.91]$} \\
Cohort 3 (rank 301 to 500) & -0.01 & 0.04 & 0.09 & 0.00 & -0.01 \\
& {$[-1.81]$} & {$[2.32]$} & {$[2.72]$} & {$[0.12]$} & {$[-1.61]$} \\
Cohort 4 (rank 501 to 700) & -0.01 & 0.04 & 0.16 & -0.00 & -0.00 \\
& {$[-1.07]$} & {$[2.06]$} & {$[4.12]$} & {$[-0.02]$} & {$[-0.06]$} \\
Cohort 5 (rank 701 to 900) & 0.01 & 0.02 & 0.24 & 0.01 & 0.01 \\
& {$[1.52]$} & {$[0.76]$} & {$[5.89]$} & {$[0.27]$} & {$[0.73]$} \\
Cohort 6 (rank 901 to 1100) & 0.01 & 0.05 & 0.18 & 0.01 & 0.01 \\
& {$[1.60]$} & {$[1.10]$} & {$[3.34]$} & {$[0.29]$} & {$[1.60]$} \\
Cohort 7 (rank 1101 to 1300) & 0.03 & 0.10 & 0.06 & 0.06 & 0.02 \\
& {$[3.97]$} & {$[1.88]$} & {$[1.18]$} & {$[1.36]$} & {$[2.37]$} \\
Cohort 8 (rank 1301 to 1500) & 0.04 & -0.10 & -0.02 & 0.03 & 0.04 \\
& {$[6.08]$} & {$[-1.26]$} & {$[-0.41]$} & {$[0.51]$} & {$[5.35]$} \\
Cohort 9 (rank 1501 to 1716) & 0.13 & 0.08 & -0.06 & -0.03 & 0.09 \\
& {$[15.21]$} & {$[0.74]$} & {$[-1.02]$} & {$[-0.52]$} & {$[10.70]$} \\
Napster & -0.03 & 0.05 & -0.05 & -0.10 & -0.03 \\
& {$[-3.38]$} & {$[2.93]$} & {$[-2.50]$} & {$[-5.30]$} & {$[-3.65]$} \\
Napster * Cohort 2 & 0.06 & 0.09 & -0.01 & 0.07 & 0.07 \\
& {$[6.55]$} & {$[3.64]$} & {$[-0.20]$} & {$[2.56]$} & {$[6.90]$} \\
Napster * Cohort 3 & 0.10 & 0.20 & 0.17 & 0.17 & 0.11 \\
& {$[10.26]$} & {$[3.75]$} & {$[3.48]$} & {$[4.92]$} & {$[9.76]$} \\
Napster * Cohort 4 & 0.13 & 0.34 & 0.19 & 0.24 & 0.14 \\
& {$[12.86]$} & {$[5.38]$} & {$[2.84]$} & {$[5.66]$} & {$[11.53]$} \\
Napster * Cohort 5 & 0.16 & 0.40 & 0.15 & 0.30 & 0.18 \\
& {$[13.92]$} & {$[4.22]$} & {$[2.41]$} & {$[5.03]$} & {$[13.74]$} \\
Napster * Cohort 6 & 0.20 & 0.45 & 0.25 & 0.31 & 0.20 \\
Napster * Cohort 7 & {$[15.74]$} & {$[3.82]$} & {$[3.36]$} & {$[4.61]$} & {$[13.84]$} \\
Napster * Cohort 8 & 0.21 & 0.37 & 0.56 & 0.23 & 0.23 \\
& {$[17.15]$} & {$[2.22]$} & {$[8.68]$} & {$[2.79]$} & {$[14.77]$} \\
Napster * Cohort 9 & 0.24 & 0.71 & 0.76 & 0.37 & 0.25 \\
Constant & {$[17.49]$} & {$[3.08]$} & {$[9.58]$} & {$[3.71]$} & {$[13.25]$} \\
Observations & 0.20 & 0.60 & 0.74 & 0.15 & 0.24 \\
R-squared & {$[14.10]$} & {$[2.34]$} & {$[8.30]$} & {$[1.71]$} & {$[12.74]$} \\
\hline \hline tsts & 0.10 & 0.05 & 0.12 & 0.14 & 0.11 \\
& {$[15.81]$} & {$[3.95]$} & {$[8.58]$} & {$[13.80]$} & {$[16.63]$} \\
& & & & & \\
& 17,160 & 4,060 & 3,073 & 4,357 & 15,175 \\
& 0.24 & 0.11 & 0.11 & 0.03 & 0.18 \\
\hline
\end{tabular}

t-stats are reported in brackets and are calculated using robust standard errors. Analyses rely on the all artists in the Pollstar concert data. The concert revenue growth rate is calculated as the log of current year concert revenues minus the log of previous year concert revenues for the same revenue rank ist in both years based on revenues in the region of analysis. Cohorts are based on national concert revenue ranks for all analyses. 
Table 7: Album Sales Growth Rate - Matched Sample of Artists

\begin{tabular}{|c|c|c|c|c|c|}
\hline & \multirow[b]{2}{*}{ National } & \multicolumn{4}{|c|}{ DMA Level } \\
\hline & & NY & LA & Chicago & Other \\
\hline \multirow[t]{2}{*}{ Cohort 2 (rank 51 to 100$)$} & -0.02 & -0.01 & 0.01 & -0.00 & -0.02 \\
\hline & {$[-1.64]$} & {$[-0.86]$} & {$[0.61]$} & {$[-0.12]$} & {$[-2.30]$} \\
\hline \multirow[t]{2}{*}{ Cohort 3 (rank 101 to 200) } & -0.03 & 0.00 & 0.01 & -0.00 & -0.03 \\
\hline & {$[-3.67]$} & {$[0.05]$} & {$[1.15]$} & {$[-0.49]$} & {$[-3.24]$} \\
\hline \multirow[t]{2}{*}{ Cohort 4 (rank 201 to 300 ) } & 0.01 & 0.01 & 0.02 & -0.01 & 0.01 \\
\hline & {$[0.70]$} & {$[0.53]$} & {$[2.26]$} & {$[-0.54]$} & {$[0.90]$} \\
\hline \multirow[t]{2}{*}{ Cohort 5 (rank 301 to 400 ) } & 0.01 & 0.04 & 0.04 & 0.01 & 0.01 \\
\hline & {$[0.94]$} & {$[2.70]$} & {$[3.77]$} & {$[1.20]$} & {$[1.09]$} \\
\hline \multirow[t]{2}{*}{ Cohort 6 (rank 401 to 500) } & 0.03 & 0.05 & 0.09 & 0.05 & 0.03 \\
\hline & {$[3.15]$} & {$[4.36]$} & {$[6.58]$} & {$[4.53]$} & {$[3.36]$} \\
\hline \multirow[t]{2}{*}{ Cohort 7 (rank 501 to 600$)$} & 0.06 & 0.12 & 0.18 & 0.11 & 0.07 \\
\hline & {$[6.13]$} & {$[5.64]$} & {$[8.13]$} & {$[7.24]$} & {$[6.18]$} \\
\hline \multirow[t]{2}{*}{ Cohort 8 (rank 601 to 704$)$} & 0.13 & 0.22 & 0.27 & 0.22 & 0.13 \\
\hline & [11.20] & {$[8.24]$} & [11.20] & {$[9.35]$} & {$[11.29]$} \\
\hline \multirow[t]{2}{*}{ Napster } & -0.17 & -0.14 & -0.06 & -0.17 & -0.18 \\
\hline & {$[-11.91]$} & {$[-11.63]$} & {$[-4.80]$} & {$[-13.52]$} & {$[-12.00]$} \\
\hline \multirow[t]{2}{*}{ Napster $*$ Cohort 2} & 0.04 & 0.04 & 0.03 & 0.05 & 0.04 \\
\hline & {$[2.64]$} & {$[2.27]$} & {$[1.85]$} & {$[3.50]$} & {$[2.56]$} \\
\hline \multirow[t]{2}{*}{ Napster $*$ Cohort 3} & 0.10 & 0.08 & 0.04 & 0.06 & 0.10 \\
\hline & {$[6.62]$} & {$[5.32]$} & {$[2.91]$} & {$[4.38]$} & {$[6.11]$} \\
\hline \multirow[t]{2}{*}{ Napster $*$ Cohort 4} & 0.05 & 0.12 & 0.05 & 0.07 & 0.05 \\
\hline & {$[3.37]$} & {$[8.08]$} & {$[3.79]$} & {$[5.29]$} & {$[2.92]$} \\
\hline \multirow[t]{2}{*}{ Napster $*$ Cohort 5} & 0.08 & 0.09 & 0.06 & 0.07 & 0.08 \\
\hline & {$[5.43]$} & {$[5.10]$} & {$[4.09]$} & {$[5.01]$} & {$[5.06]$} \\
\hline \multirow[t]{2}{*}{ Napster $*$ Cohort 6} & 0.09 & 0.10 & 0.03 & 0.04 & 0.09 \\
\hline & {$[5.48]$} & {$[6.44]$} & {$[1.74]$} & {$[2.61]$} & {$[5.13]$} \\
\hline \multirow[t]{2}{*}{ Napster $*$ Cohort 7} & 0.08 & 0.07 & -0.03 & 0.00 & 0.08 \\
\hline & {$[4.96]$} & {$[2.67]$} & {$[-1.30]$} & {$[0.19]$} & {$[4.84]$} \\
\hline \multirow[t]{2}{*}{ Napster $*$ Cohort 8} & 0.03 & -0.03 & -0.10 & -0.10 & 0.02 \\
\hline & {$[1.62]$} & {$[-1.03]$} & {$[-3.83]$} & {$[-3.94]$} & {$[1.32]$} \\
\hline \multirow[t]{2}{*}{ Constant } & 0.08 & 0.03 & 0.02 & 0.05 & 0.09 \\
\hline & {$[9.03]$} & {$[3.09]$} & {$[2.14]$} & {$[5.61]$} & {$[9.76]$} \\
\hline Observations & 5,624 & 5,591 & 5,608 & 5,617 & 5,624 \\
\hline R-squared & 0.33 & 0.10 & 0.13 & 0.21 & 0.34 \\
\hline
\end{tabular}

t-stats are reported in brackets and are calculated using robust standard errors. Analyses rely on the matched artist sample for concerts and albums. The album sales growth rate is calculated as the log of current year album sales minus the log of previous year album sales for the same sale rank artist in both years based on album sales in the region of analysis. Cohorts are based on national album sales ranks for all analyses. 
Table 8: Concert Revenue Growth Rate - Matched Sample of Artists

\begin{tabular}{|c|c|c|c|c|c|}
\hline & \multirow[b]{2}{*}{ National } & \multicolumn{4}{|c|}{ Broadband Penetration Quartile } \\
\hline & & $0-25 \%$ & $25 \%-50 \%$ & $50 \%-75 \%$ & $75 \%-100 \%$ \\
\hline \multirow[t]{2}{*}{ Cohort 2 (rank 51 to 100$)$} & -0.05 & 0.02 & -0.07 & 0.02 & -0.03 \\
\hline & {$[-2.28]$} & {$[0.61]$} & {$[-3.08]$} & {$[1.20]$} & {$[-1.45]$} \\
\hline \multirow{2}{*}{ Cohort 3 (rank 101 to 200$)$} & -0.04 & 0.05 & -0.05 & 0.02 & -0.02 \\
\hline & {$[-2.63]$} & {$[1.57]$} & {$[-2.57]$} & {$[1.24]$} & {$[-1.08]$} \\
\hline \multirow[t]{2}{*}{ Cohort 4 (rank 201 to 300$)$} & -0.03 & 0.12 & 0.03 & 0.04 & 0.02 \\
\hline & {$[-1.60]$} & {$[2.60]$} & {$[1.67]$} & {$[1.98]$} & {$[0.75]$} \\
\hline \multirow[t]{2}{*}{ Cohort 5 (rank 301 to 409) } & 0.03 & 0.04 & 0.12 & 0.08 & 0.10 \\
\hline & {$[1.94]$} & {$[0.62]$} & {$[5.40]$} & {$[2.96]$} & {$[4.50]$} \\
\hline \multirow[t]{2}{*}{ Napster } & -0.05 & 0.14 & -0.09 & -0.10 & -0.02 \\
\hline & {$[-2.15]$} & {$[3.88]$} & {$[-3.78]$} & {$[-4.73]$} & {$[-0.69]$} \\
\hline \multirow[t]{2}{*}{ Napster $*$ Cohort 2} & 0.12 & -0.01 & 0.16 & 0.07 & 0.12 \\
\hline & {$[3.93]$} & {$[-0.17]$} & {$[5.40]$} & {$[2.19]$} & {$[3.26]$} \\
\hline \multirow[t]{2}{*}{ Napster $*$ Cohort 3} & 0.17 & 0.08 & 0.20 & 0.20 & 0.16 \\
\hline & {$[6.50]$} & {$[1.58]$} & {$[7.45]$} & {$[6.44]$} & {$[4.94]$} \\
\hline \multirow[t]{2}{*}{ Napster $*$ Cohort 4} & 0.21 & 0.13 & 0.18 & 0.28 & 0.21 \\
\hline & {$[7.65]$} & {$[2.05]$} & {$[6.28]$} & {$[8.20]$} & {$[5.75]$} \\
\hline \multirow[t]{2}{*}{ Napster $*$ Cohort 5} & 0.23 & 0.31 & 0.16 & 0.30 & 0.20 \\
\hline & {$[8.40]$} & {$[4.20]$} & {$[4.90]$} & {$[7.46]$} & {$[4.87]$} \\
\hline \multirow[t]{2}{*}{ Constant } & 0.12 & 0.10 & 0.13 & 0.12 & 0.11 \\
\hline & {$[7.62]$} & {$[4.38]$} & {$[8.40]$} & {$[9.87]$} & {$[5.97]$} \\
\hline Observations & 3,272 & 1,475 & 2,725 & 2,295 & 2,829 \\
\hline R-squared & 0.20 & 0.12 & 0.12 & 0.11 & 0.12 \\
\hline
\end{tabular}

t-stats are reported in brackets and are calculated using robust standard errors. Analyses rely on the matched artist sample for concerts and albums. The concert revenue growth rate is calculated as the log of current year concert revenues minus the log of previous year concert revenues for the same revenue rank artist in both years based on revenues in the region of analysis. Cohorts are based on national concert revenue ranks for all analyses. 
Table 9: Concert Revenue Growth Rate - Pollstar Dataset

\begin{tabular}{|c|c|c|c|c|c|}
\hline & \multirow[b]{2}{*}{ National } & \multicolumn{4}{|c|}{ Broadband Penetration Quartile } \\
\hline & & $0-25 \%$ & $25 \%-50 \%$ & $50 \%-75 \%$ & $75 \%-100 \%$ \\
\hline \multirow[t]{2}{*}{ Cohort 2 (rank 101 to 300$)$} & -0.01 & 0.01 & -0.01 & -0.00 & -0.01 \\
\hline & {$[-1.58]$} & {$[0.82]$} & {$[-0.79]$} & {$[-0.65]$} & {$[-0.59]$} \\
\hline \multirow[t]{2}{*}{ Cohort 3 (rank 301 to 500) } & -0.01 & -0.00 & 0.02 & 0.01 & -0.00 \\
\hline & {$[-1.81]$} & {$[-0.29]$} & {$[1.94]$} & {$[1.02]$} & {$[-0.17]$} \\
\hline \multirow[t]{2}{*}{ Cohort 4 (rank 501 to 700$)$} & -0.01 & -0.01 & 0.06 & 0.02 & -0.00 \\
\hline & {$[-1.07]$} & {$[-0.54]$} & {$[6.99]$} & {$[2.43]$} & {$[-0.20]$} \\
\hline \multirow[t]{2}{*}{ Cohort 5 (rank 701 to 900$)$} & 0.01 & -0.01 & 0.09 & 0.05 & -0.02 \\
\hline & {$[1.52]$} & {$[-0.70]$} & {$[8.84]$} & {$[4.63]$} & {$[-1.53]$} \\
\hline \multirow[t]{2}{*}{ Cohort 6 (rank 901 to 1100$)$} & 0.01 & 0.02 & 0.10 & 0.05 & -0.03 \\
\hline & {$[1.60]$} & {$[1.15]$} & {$[9.00]$} & {$[3.62]$} & {$[-1.75]$} \\
\hline \multirow[t]{2}{*}{ Cohort 7 (rank 1101 to 1300 ) } & 0.03 & 0.01 & 0.14 & 0.06 & -0.03 \\
\hline & {$[3.97]$} & {$[0.59]$} & {$[10.14]$} & {$[4.54]$} & {$[-1.91]$} \\
\hline \multirow[t]{2}{*}{ Cohort 8 (rank 1300 to 1500$)$} & 0.04 & 0.07 & 0.14 & 0.06 & -0.03 \\
\hline & {$[6.08]$} & {$[2.70]$} & {$[9.13]$} & {$[3.31]$} & {$[-1.78]$} \\
\hline \multirow[t]{2}{*}{ Cohort 9 (rank 1501 to 1716 ) } & 0.13 & -0.04 & 0.24 & 0.14 & -0.04 \\
\hline & {$[15.21]$} & {$[-1.66]$} & {$[9.46]$} & {$[6.45]$} & {$[-1.77]$} \\
\hline \multirow[t]{2}{*}{ Napster } & -0.03 & -0.03 & -0.03 & -0.01 & -0.00 \\
\hline & {$[-3.38]$} & {$[-2.40]$} & {$[-2.92]$} & {$[-0.61]$} & {$[-0.38]$} \\
\hline \multirow[t]{2}{*}{ Napster $*$ Cohort 2} & 0.06 & 0.06 & 0.08 & 0.07 & 0.06 \\
\hline & {$[6.55]$} & {$[4.01]$} & {$[7.10]$} & {$[4.39]$} & {$[3.54]$} \\
\hline \multirow[t]{2}{*}{ Napster $*$ Cohort 3} & 0.10 & 0.16 & 0.14 & 0.17 & 0.12 \\
\hline & {$[10.26]$} & {$[9.55]$} & [10.93] & {$[9.73]$} & {$[6.18]$} \\
\hline \multirow[t]{2}{*}{ Napster $*$ Cohort 4} & 0.13 & 0.23 & 0.16 & 0.23 & 0.17 \\
\hline & [12.86] & [11.98] & [10.95] & [11.53] & {$[6.67]$} \\
\hline \multirow[t]{2}{*}{ Napster $*$ Cohort 5} & 0.16 & 0.27 & 0.18 & 0.28 & 0.23 \\
\hline & [13.92] & {$[12.48]$} & [11.36] & [10.93] & {$[7.37]$} \\
\hline \multirow[t]{2}{*}{ Napster $*$ Cohort 6} & 0.20 & 0.35 & 0.25 & 0.37 & 0.36 \\
\hline & {$[15.74]$} & {$[12.60]$} & [13.59] & {$[12.52]$} & [10.28] \\
\hline \multirow[t]{2}{*}{ Napster $*$ Cohort 7} & 0.21 & 0.34 & 0.31 & 0.35 & 0.43 \\
\hline & {$[17.15]$} & {$[12.87]$} & [13.02] & [11.08] & [10.08] \\
\hline \multirow[t]{2}{*}{ Napster $*$ Cohort 8} & 0.24 & 0.34 & 0.30 & 0.43 & 0.48 \\
\hline & [17.49] & {$[9.27]$} & [11.53] & [10.48] & {$[9.30]$} \\
\hline \multirow[t]{2}{*}{ Napster $*$ Cohort 9} & 0.20 & 0.54 & 0.31 & 0.40 & 0.50 \\
\hline & [14.10] & {$[13.94]$} & {$[8.73]$} & {$[8.53]$} & {$[7.69]$} \\
\hline \multirow[t]{2}{*}{ Constant } & 0.10 & 0.12 & 0.09 & 0.07 & 0.09 \\
\hline & {$[15.81]$} & [17.95] & [13.76] & [11.28] & [11.85] \\
\hline Observations & 17,160 & 8,089 & 9,762 & 9,473 & 11,045 \\
\hline R-squared & 0.24 & 0.18 & 0.27 & 0.22 & 0.11 \\
\hline
\end{tabular}

t-stats are reported in brackets and are calculated using robust standard errors. Analyses rely on the all artists in the Pollstar concert data. The concert revenue growth rate is calculated as the log of current year concert revenues minus the log of previous year concert revenues for the same revenue rank artisg $1 \mathrm{n}$ both years based on revenues in the region of analysis. Cohorts are based on national concert revenue ranks for all analyses. 
Table 10: Album Sales Growth Rate - Matches Sample of Artists

\begin{tabular}{|c|c|c|c|c|c|}
\hline & \multirow[b]{2}{*}{ National } & \multicolumn{4}{|c|}{ Broadband Penetration Quartile } \\
\hline & & $0-25 \%$ & $25 \%-50 \%$ & $50 \%-75 \%$ & $75 \%-100 \%$ \\
\hline \multirow[t]{2}{*}{ Cohort 2 (rank 51 to 100$)$} & -0.02 & -0.04 & -0.02 & -0.02 & -0.02 \\
\hline & {$[-1.64]$} & {$[-4.15]$} & {$[-2.25]$} & {$[-1.44]$} & {$[-1.46]$} \\
\hline \multirow[t]{2}{*}{ Cohort 3 (rank 101 to 200) } & -0.03 & -0.01 & -0.03 & -0.03 & -0.02 \\
\hline & {$[-3.67]$} & {$[-1.66]$} & {$[-3.58]$} & {$[-2.78]$} & {$[-2.73]$} \\
\hline \multirow[t]{2}{*}{ Cohort 4 (rank 201 to 300$)$} & 0.01 & 0.03 & 0.01 & 0.01 & -0.01 \\
\hline & {$[0.70]$} & {$[2.97]$} & {$[0.55]$} & {$[0.92]$} & {$[-1.15]$} \\
\hline \multirow[t]{2}{*}{ Cohort 5 (rank 301 to 400 ) } & 0.01 & 0.04 & 0.01 & 0.02 & 0.01 \\
\hline & {$[0.94]$} & {$[4.09]$} & {$[0.78]$} & {$[1.57]$} & {$[1.41]$} \\
\hline \multirow[t]{2}{*}{ Cohort 6 (rank 401 to 500) } & 0.03 & 0.07 & 0.03 & 0.04 & 0.04 \\
\hline & {$[3.15]$} & {$[7.29]$} & {$[3.21]$} & {$[4.36]$} & {$[3.81]$} \\
\hline \multirow[t]{2}{*}{ Cohort 7 (rank 501 to 600$)$} & 0.06 & 0.12 & 0.07 & 0.09 & 0.06 \\
\hline & {$[6.13]$} & {$[11.25]$} & {$[6.82]$} & {$[7.90]$} & {$[6.38]$} \\
\hline \multirow[t]{2}{*}{ Cohort 8 (rank 601 to 704 ) } & 0.13 & 0.22 & 0.15 & 0.15 & 0.15 \\
\hline & {$[11.20]$} & {$[11.30]$} & {$[11.37]$} & [12.20] & {$[9.66]$} \\
\hline \multirow[t]{2}{*}{ Napster } & -0.17 & -0.14 & -0.16 & -0.12 & -0.14 \\
\hline & {$[-11.91]$} & {$[-9.45]$} & {$[-11.00]$} & {$[-8.41]$} & {$[-10.30]$} \\
\hline \multirow[t]{2}{*}{ Napster $*$ Cohort 2} & 0.04 & 0.06 & 0.05 & 0.04 & 0.05 \\
\hline & {$[2.64]$} & {$[3.67]$} & {$[3.19]$} & {$[2.49]$} & {$[3.10]$} \\
\hline \multirow[t]{2}{*}{ Napster $*$ Cohort 3} & 0.10 & 0.07 & 0.10 & 0.09 & 0.08 \\
\hline & {$[6.62]$} & {$[4.74]$} & {$[6.66]$} & {$[6.24]$} & {$[5.22]$} \\
\hline \multirow[t]{2}{*}{ Napster $*$ Cohort 4} & 0.05 & 0.04 & 0.05 & 0.04 & 0.09 \\
\hline & {$[3.37]$} & {$[2.38]$} & {$[3.02]$} & {$[2.97]$} & {$[5.95]$} \\
\hline \multirow[t]{2}{*}{ Napster $*$ Cohort 5} & 0.08 & 0.07 & 0.08 & 0.07 & 0.09 \\
\hline & {$[5.43]$} & {$[4.28]$} & {$[5.36]$} & {$[4.79]$} & {$[6.05]$} \\
\hline \multirow[t]{2}{*}{ Napster $*$ Cohort 6} & 0.09 & 0.06 & 0.08 & 0.06 & 0.08 \\
\hline & {$[5.48]$} & {$[3.74]$} & {$[4.89]$} & {$[3.93]$} & {$[4.99]$} \\
\hline \multirow[t]{2}{*}{ Napster $*$ Cohort 7} & 0.08 & 0.03 & 0.06 & 0.05 & 0.07 \\
\hline & {$[4.96]$} & {$[1.66]$} & {$[3.39]$} & {$[3.04]$} & {$[4.38]$} \\
\hline \multirow[t]{2}{*}{ Napster $*$ Cohort 8} & 0.03 & -0.06 & -0.01 & 0.00 & 0.01 \\
\hline & {$[1.62]$} & {$[-2.42]$} & {$[-0.38]$} & {$[0.03]$} & {$[0.71]$} \\
\hline \multirow[t]{2}{*}{ Constant } & 0.08 & 0.05 & 0.06 & 0.04 & 0.05 \\
\hline & {$[9.03]$} & {$[5.94]$} & {$[6.13]$} & {$[4.45]$} & {$[5.53]$} \\
\hline Observations & 5,624 & 5,623 & 5,623 & 5,622 & 5,623 \\
\hline R-squared & 0.33 & 0.25 & 0.31 & 0.30 & 0.23 \\
\hline
\end{tabular}

t-stats are reported in brackets and are calculated using robust standard errors. Analyses rely on the matched artist sample for concerts and albums. The album sales growth rate is calculated as the log of current year album sales minus the log of previous year album sales for the same sale rank artist in both years based on album sales in the region of analysis. Cohorts are based on national album sales ranks for all analyses. 